\title{
Research on the Path and Practice of Ideological Leadership in the Platform of Changing Classes in Colleges and Universities
}

\author{
Feng Suo ${ }^{1,}$,, $\mathrm{Yu} \mathrm{Xiao}{ }^{2, b^{*}}$ \\ ${ }^{1}$ Department of Ideological and Political Education, The Chinese University of Hong Kong, Shatin, New Territories, \\ Hong Kong, China \\ ${ }^{2}$ Department of Ideological and Political Education, The Chinese University of Hong Kong, Shatin, New Territories, \\ Hong Kong, China \\ a5361032@qq.com \\ b*877148979@qq.com
}

\begin{abstract}
"Ideological work is an extremely important work of the party, which is related to the flag, the road and the national political security." Colleges and universities are the main positions led by ideology. They are facing many challenges, such as pluralism and openness, virtuality and concealment, interaction and decentralization. As the most influential comprehensive online education platform in China, E-class's education and teaching, life service and cultural entertainment functions can provide new ideas to solve the problems faced by college students' ideological leadership. Therefore, the network platform of "E-class" in Colleges and universities must focus on the coordination of education and entertainment to produce emotional resonance; strengthen information supervision, cultivate opinion leaders; update the content of discourse, and innovate the way of communication, focusing on improving the guiding power of ideology, the explanatory power of practical problems and the appeal of ideological discourse, so as to carry out the mainstream consciousness in Colleges and universities The construction of form leadership.
\end{abstract}

Keywords: energy, machinery, chemistry, materials

\section{高校易班平台意识形态领导权路径与实践研究}

\author{
丰硕 1 , a 于潇 $2, \mathrm{~b}^{*}$
}

${ }^{1}$ 桂林电子科技大学马克思主义学院, 桂林, 广西, 中国

2 桂林电子科技大学马克思主义学院, 桂林, 广西, 中国

a5361032@qq.com

b*877148979@qq.com

\begin{abstract}
摘要
“意识形态工作是党的一项极端重要的工作，关乎旗帜、关乎道路、关乎国家政治安全。”高校是意 识形态引领的主阵地, 当前面临着多元性与开放性、虚拟性与隐匿性、交互性与去中心化等众多挑战。 易班作为全国最具影响力的综合性网络教育平台, 其教育教学、生活服务和文化娱乐功能可以为解决 大学生意识形态领导权所面临的问题提供新的思路。为此, 高校 “易班” 网络平台必须从注重教育性 和娱乐性相协调，产生情感共振；加强信息监管，培育意见领袖; 更新话语内容，创新传播方式三方 面入手, 着重提升意识形态的引导力、对现实问题的解释力以及意识形态话语吸引力, 有针对性地进 行高校主流意识形态领导权的建构。
\end{abstract}

关键词: 高校, 易班平台, 意识形态领导权 
同感。

\section{1. 前言}

“意识形态工作是党的一项极为重要的工作。” 高 校是意识形态建设的主阵地, 习近平总书记指出: “办 好我国高等教育, 必须坚持党的领导, 牢牢掌握党对高 校工作的领导权, 使高校成为坚持党领导的坚强阵地。” 随着互联网技术的快速发展, 各类社会思潮通过网络媒 体不断渗透, 大学校园内各种意识形态形成了激烈的对 决。为有效应对大学校园内意识形态斗争日趋复杂的形 势, 高校必须不断开展网络思想政治教育新媒体平台工 作的实践探索, 引导大学生形成正确的价值观, 以防止 其在各种意识形态冲击下随波逐流。因此, 高校必须高 度重视大学生意识形态工作领导权建设, 充分挖掘高校 “易班” 网络互动社区对于主流意识形态教育的潜在价 值, 通过深入分析当前高校意识形态工作领导权面临的 挑战, 进而探寻高校加强意识形态工作领导权的有效途 径。

\section{2. 易班平台是培育高校主流意识形态的网络 主阵地}

“人自由而全面的发展是马克思论断的人类发展 的最高目标。马克思主义关于人的全面发展理论主要包 括人的主体性发展、人的实践的发展和人的社会关系的 发展”。高校构建网络思想政治教育易班平台, 目的在 于促进思想政治教育的健康有序发展。当前, 易班平台 在高校主流意识形态建设方面发挥着网络主阵地的作 用。

首先, 易班平台的教育教学功能有利于强化高校对 主流意识形态的引领。易班平台特有的综合性、确定性、 真实性特点使其能够有效的整合教育教学资源, 改变信 息传统单向发布模式, 实现教育主客体之间的互动交 流。教育工作者通过搭建 “易班” 班级管理模块, 方便 快捷的分享学习资料、在线答疑辅导作业、组织社团活 动以及开展道德和法律知识讲座等, 引导学生进行网上 互动和线下交流, 将说教方式变为建议和提醒, 帮助学 生正确应对网络多元化思潮对意识形态领域的冲击。同 时班主任与辅导员还可以通过发布话题和投票的形式, 及时了解大学生的思想状况, 针对当前高校学生关注的 公共事务、社会热点、国际焦点等热点话题建立 “诉求 一回应” 反馈机制，借助易班这一新媒体平台及时发布 消息回应质疑，强化高校对主流意识形态的引领作用。

其次, 易班平台的生活服务功能有助于提升大学生 对主流意识形态的认同。“易班智慧校园” 是一个以服 务学生为中心, 全方位满足当代大学生学习和生活需要 的综合信息服务平台, 该平台将校内现有的教务管理系 统、学工系统、一卡通系统、就业系统、图书馆等数据 库予以整合, 真正实现一站式服务。友好的界面, 迅捷 化的操作, 各大数据库的集成, 不仅提高了学生工作的 效率, 更帮助其解决了学习、生活、工作中的各种困扰, 从而提升对学校、班级的集体归属感和主流意识形态认
最后, 易班平台的文化娱乐功能有利于增强大学生 对主流意识形态的接受度。易班平台基于已有的高校师 生用户数据，采用线上线下相结合的 “ $020 ”$ (Online To Offline) 模式, 开展当代大学生喜闻乐见的兼具知识性 和娱乐性的校园文化活动, 例如举办 “校园歌手大赛” 、 “易班达人秀” “易班 LOGO 设计大赛” 等, 将易班平 台的形象进行展示, 吸引广大师生进行参与互动和点赞 评论，既丰富了校园文化生活也实现了线上线下平台的 联动增益效应。同时，依托易班 “轻应用” 快搭平台， 实现主题活动的报名、抢票、评选、分享等, 通过活动 传递主流文化与正能量, 推动网络思想文化建设, 引导 大学生形成正确科学的世界观与价值观, 增强大学生对 主流意识形态的接受度。

\section{3. 高校意识形态领导权建构所面临的主要问 题}

\section{1. 多元性与开放性的网络格局弱化了主流 意识形态的整合力}

随着网络媒介传播载体的纵深发展, 以微博、微信 以及移动客户端 (APP) 等平台为载体的新兴媒介迅速 崛起, 赢得了高校学生群体的喜爱。其主体多元化、内 容开放化、传播及时化的特征不同于以往传统媒体的传 播方式与场景, 对大学生这一受众群体的心理和行为习 惯产生了影响, 主流意识形态的主导力相较于传统媒体 而言被削弱。大学生利用网络媒体开放多元化的特点在 网络社区自由表达个人观点，根据相同的目标和期望以 及相似用户行为结成网络社群, 一方面为高校主流意识 形态教育提供了个性化和多样化的渠道, 但同时也因网 络立法和管控的不完善增加了网络意识形态治理的难 度, 弱化了主流意识形态的主导力。

网络传输的便捷性和低门槛为公众自由发声提供 了低廉的技术平台, 在网络媒体时代, “人人都有麦克 风”，多样化的传播渠道使每个人的话语权得到了最大 程度的彰显，但与此同时 “历史虚无主义”、“自由主 义”、“普世价值论” “意识形态多元化” 等错误思潮 不断涌现构成强大的网络與论思潮, 对大学生群体价值 观产生深刻的影响, 逐渐改变着传统主流意识形态建构 的价值生态。

\section{2. 虚拟性与隐匿性的网络特征增加了主流 意识形态管控的难度}

当前网络空间意识形态出现了新的变化, 网络为公 众创造了一个虚拟的环境, 表面上似乎离现实很远。网 络空间的虚拟身份使大学生穿上了 “隐身衣”, 可以脱 离现实束缚在平等、自由的网络环境中畅所欲言, 一个 以虚拟技术为支撑的真实社交圈正在逐渐形成。借助数 


\section{4. 基于易班网络思政平台提升意识形态领导 权的实践路径} 文字等形式传递信息、表达意见。在互联网的世界里, 良莠不齐的海量信息几乎没有国界、地域和监管的限 制, 网络的虚拟性增加了非主流意识形态治理的难度, 网络的隐匿性削弱了传统主流意识形态的沟通功能。

从网络技术的角度看, 因网络信息无法追踪到特定 的人或具体的组织, 所以在技术上很难控制无形的公共 匿名行动。同时, 现实世界中存在的个人观点和意见通 过网络虚拟世界被客观地表达出来, 其意识形态也离不 开现实社会。网络意识形态对虚拟行为主体的影响也会 延伸反应在现实社会中。一旦网络與论处理不当, 往往 会在现实社会中酿成严重的群体事件, 这就需要我们高 度重视网络意识形态平台建设, 占领网络意识形态建设 的制高点, 建立起意识形态安全的网络防火墙, 以灵活 的方式和方法使公众在网络空间接受意识形态的影响。

\section{3. 交互性与去中心化的网络结构冲击了意 识形态传统传播方式}

新兴网络媒体海量信息存储以及信息整合功能突 破了传统报刊、广播、电视等媒体版面和时间的限制, 特别是网络链接和检索功能使信息的整合更加高效便 捷, 从而打破了传统媒体对高校学生意识形态话语权的 垄断地位, 成为新时代最具欢迎、更富活力的大众媒介。 新兴媒体的交互性在一定意义上有助于在大学生之间 开展主流意识形态教育, 大学生通过微信、微博、易班 等媒体平台, 与其他学者进行思想交流与学术互动, 在 此过程中树立起正确的价值导向和人生目标。但另一方 面, 高校学生正处于世界观、人生观、价值观的形成和 发展的阶段, 面对纷繁复杂的网络世界缺乏理性的判断 和思考能力。新兴媒体使信息以数据流的形式高速的在 网络中传播, 大学生群体不仅可以在网络上获取所需要 的信息, 也可以通过多种渠道在各平台自由的表达自身 的看法。如果不良信息和错误的价值观念以文字、图片、 视频等形式在大学生群体之间进行传播, 这种网络的交 互性特点将增加高校主流意识形态教育的难度。

在传统媒体时代, 信息的传播通常是以某一主体为 中心, 其他主体为节点的。中心决定着节点的信息走向, 节点无法脱离中心而单独存在。进入新媒体时代, 信息 的传播由单一主体的线性传播转化为多元主体的网状 传播模式, 并形成了链状、环状以及树状的对话结构, 传统媒体对意识形态话语权的主导地位减弱, 开启了意 识形态话语权的 “去中心化” 时代。这在一定程度上冲 击了教育者对意识形态话语权严格把控的局面, 弱化了 党政机关所担任的 “把关人” 的角色, 通过议题设置主 导公众與论的难度大大增加。因此, 只有重新调整意识 形态话语权在官方媒体和自媒体、教育者与受教育者之 间分配的比重, 提高意识形态话语权的掌控能力、掌控 方法、掌控条件, 才能更好地应对高校意识形态教育所 面临的挑战。
“国家意识形态机器的相对重要性使得教育和媒 体日益成为资本主义社会最主要的意识形态机器。”西 方敌对势力意图对我国进行意识形态领域的文化渗透, 必然会采取一切手段占领高校这个前沿阵地。面对新媒 体时代的各种挑战, 我们需要通过加强信息监管、培育 意见领袖、更新话语内容、创新传播手段等方式，切实 提升主流意识形态的话语权与主导权, 从而发挥高校作 为我国进行社会主义意识形态宣传主阵地的战略价值。

\section{1. 注重教育性和娱乐性相协调, 产生情感共 振, 提升意识形态引导力}

牢牢掌握高校主流意识形态领导权, 需要把握好情 感这一重要的纽带, 这是当下主流意识形态教育的客观 要求。基于情感价值的主流意识形态教育在思想上更易 于产生共鸣, 在精神上更具有感染力和亲和力, 是凝聚 社会共识、激发情感共振的 “粘合剂”。提升高校主流 意识形态的引导力要着重从以下两方面入手。

首先, 坚持教育性原则, 充分发挥其教育资源优势。 易班平台应着力打造与当代大学生健康成长需求相符 合的网络思想政治教育内容, 融合优质的教育、文化和 创新创业课程, 全方位满足大学生的学习、生活、发展 需要。例如以慕课、易班课堂、智慧课堂等形式将跨区 域、跨高校的网络学习资源进行共享。同时, 启动学生 精细化管理平台探索 “精准思政” 育人模式，通过网格 化管理和大数据分析大学生的行为偏好进行有针对性 的内容投送, 根据学生的网络生活状况, 有机联系网络 学习、日常生活, 并密切结合生活服务、关怀性教育。 为青年提供更为通俗化, 更具吸引力、兴趣力、选择力 的信息内容, 有效解决当前网络思想政治教育方式单 一、内容刻板, 针对性不强的问题, 着力提升主流意识 形态话语的时代感与层次感, 进而凝聚情感脉搏和价值 共识。

其次, 注重娱乐性应用研发, 增加用户 “粘度”。 苏联教育家苏霍姆林斯基曾说过: “任何一种教育现象 在其中越少感觉到教育者的意图, 它的教育效果就越 大。”娱乐性应用程序能够发挥主流意识形态潜移默化 的教育影响, 产生 “春风化雨润物无声” 的效果。当前 易班 APP 线上育人内容以校园活动宣传类信息推送为 主, 师生黏度不高, 难以满足当代师生多元获取信息的 需求。根据用户群体的兴趣和网络使用习惯, 易班有必 要进一步加强娱乐性应用的研究开发工作。易班可以从 当前国内发展较好、用户喜爱度高的社交网络产品中借 鉴经验, 在易班平台设置群聊、视频聊天和语音对讲等 功能并且实现易班账号与 QQ 号、微信号、新浪微博号 等其他社交媒体账号的关联, 使易班真正融入到学生的 社交娱乐之中。除此之外, 易班建设中也应当吸收和借 鉴一些新兴网络话语的传播经验, 如 “萌萌哒” “马克 思是个 90 后”, 研究此类话语的构造与类型, 使网络 
真正做到 “入耳、入脑、入心”。学校党政部门应当充

流行性话语融入思想政治教育元素, 保障意识形态话语 的时代性和生命力, 将意识形态教育真正深入到新媒体 时代的网络社交中, 以保持新时代意识形态话语的权威 性。

\section{2. 加强信息监管, 培育意见领袖, 增进意识 形态对现实问题的解释力}

由于网络舆论的低门槛和匿名性的特点, 人们可以 在互联网上自由的发表言论，这就给西方敌对势力以利 用的机会，在发布的信息标题上多使用具有煽动性的表 达吸引阅读，在文章内容上多使用带有偏离事实本身和 倾向性的言论。一旦不实信息以链式方式无限发散出 去，在传播上就容易形成网络信息的多米诺骨牌效应和 蝴蝶效应。而当前大学生由于鉴别能力相对缺乏, 如果 不负责任的转发缺乏客观事实或者捕风捉影的信息, 很 容易对社会风气产生不良影响，因此处于网络环境中， 高校加强信息监管尤为重要。具体来说, 一是要建立集 网络监测和网络人才管理于一体的 “易班” 平台监管系 统。易班平台可以利用大数据技术和网络舆情分析系统 将获取的海量数据进行动态跟踪和分析挖掘, 对反映本 校大学生思想动态的文章和评论进行判别定性, 一旦发 现安全隐患, 及时反应给高校有关部门, 由其开展有针 对性的谣言澄清、與情引导和教育活动, 弘扬校园网络 文化正能量。二是要加强队伍建设, 注重 “意见领袖” 的模范带头作用。校易班要充分发挥各学院易班工作站 的共建优势资源, 进一步强化以 “易班” 为龙头的 “一 轴多翼” 线上线下阵地联盟运作机制。搭建学校易班网 络育人教师团队一研究生工作团队一校易班工作站一 学院易班工作站 4 级育人团队, 培养一批网络技术水平 高、问题处理能力强和掌握意识形态教育方法的综合性 人才队伍。同时也要发挥 “意见领袖” 的作用, 利用当 代大学生的从众心理, 引领舆论的方向。

\section{3. 更新话语内容, 创新传播方式, 增强意识 形态话语吸引力}

牢牢掌握高校主流意识形态领导权，从大学生实际 需要出发, 更新高校意识形态话语体系是关键。要将生 硬的思想政治理论话语转化为大众喜闻乐见的、通俗 的、大众化的话语, 使话语内容贴近日常生活, 以大学 生熟悉的方式表达。易班平台作为高校教育教学、生活 服务、文化娱乐的综合性互动社区, 能够提供丰富多彩 的文化信息服务。因此, 易班主流意识形态教育应根植 于中华优秀传统文化、社会主义核心价值体系中, 话语 内容的选择要充分考虑传统和当代的优秀文化, 用现代 化和极具创新思维的方式提炼文化精粹, 并以符合当代 大学生需求的方式予以呈现, 使主流意识形态教育能够
分吸收和借鉴新兴网络话语的传播经验，制作推送普法 教育、习近平新时代中国特色社会主义思想、“易图看 懂-广西民间故事中的社会主义核心价值观” 等贴近大 学生心理与行为特点的系列育人产品, 使易班网络育人 的正能量传播润育无声。

在网络思想政治内容建设上下足功夫的同时，也要 充分利用多种传播手段，进一步强化各个媒介间的融 合，打造具有鬼力的主流意识形态的易班平台，学校应 当充分发挥学院易班二级工作站阵地作用, 赋权增能, 统一发声, 将易班网络育人与学院实际相结合, 解决现 有媒体错综复杂、各自为阵、活动重复开展的共性问题, 为校园网络文化统一有序开展提供平台、技术、人员等 支持，使其让其为我所用，共同发声，引导主流思想與 论。

\section{项目基金}

本文为桂林电子科技大学党的十九大精神研究专 项课题《基于易班平台牢牢掌握大学生意识形态领导权 研究》 (US18036Y) 的阶段性成果之一。

\section{REFERENCES}

[1] Bob Franklin. (2008) The key concept of Journalism: ideological state machine entry. Peking University Press, Beijing.

[2] Liu Kang. (2019) The dual dilemma and construction path of the discourse power of the mainstream ideology under the environment of "decentralization and decentralization". Research on Chinese youth,5:102-109.

[3] Wang Yan. (2018) The construction of the discourse power of the mainstream ideology in the new era. Marxist Research,7:60-69.

[4] Wang Zongli,Zhou Fang. (2018) The impact of network new media on the ideological security of colleges and universities and the Countermeasures. Research on Ideological Education, 10:125-128.

[5] Ding Kai,Song Linze. (2018) On the construction of the discourse power of Ideological and political education in Colleges and universities in the era of self media. Research on Ideological Education,6:134-138. 